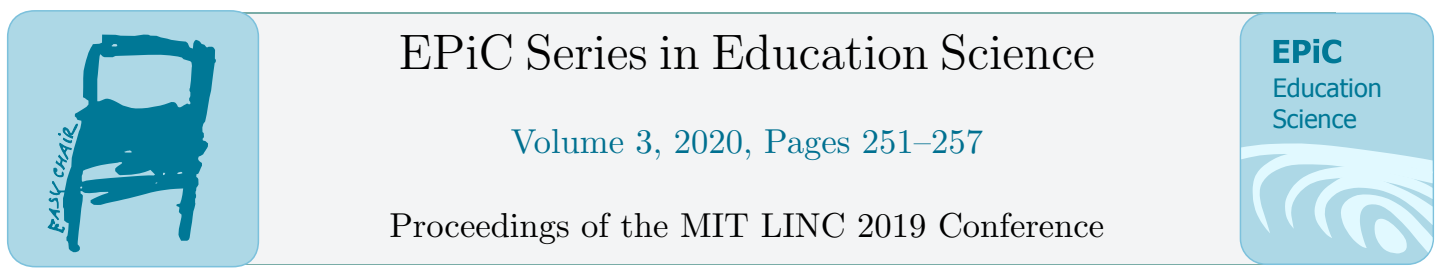

\title{
Innovation in Education offering free education to African refugees: A Case Study from Argentina
}

\author{
Jennifer Verschoor \\ St Andrew's Scots School jennifer.verschoor@sanandres.esc.edu.ar
}

\begin{abstract}
This paper will provide details of implementing the Kakuma Project in different schools in Argentina. The Kakuma Project offers free education to African refugees via Skype. Students from Argentina communicated online with students in a refugee camp in Kenya. Argentine and African students are the center of the learning process by creating content and interacting with each other. The author of this paper has been selected as a Kakuma Project Ambassador in 2016. The objective of this paper is to describe the process of implementing a global student-centered collaborative project called Kakuma Project using technology to enhance learning and teaching global awareness.
\end{abstract}

\section{Introduction}

The Kakuma Project offers free education to African refugees via Skype. The Kakuma camp currently houses 200,000 refugees who fled from war and hunger in 
Somalia, Burundi, DR Congo, Sudan, South Sudan, and other conflict-ridden regions in sub-Saharan Africa. [1].

At Kakuma, $55 \%$ of all refugees are children and people living in the camp cannot leave the camp without a special permission, so the opportunities to learn and work towards a more secure future are severely limited. Koen Timmers, a Microsoft Innovative Educator and Global Teacher Prize finalist, from Belgium set up the project back in April 2015 and has had several setbacks at the beginning. During a Skype call with an outreach officer in the Kakuma refugee camp, Timmers promised him to help increase the level of education in the camp by offering free Skype lessons to the refugee students.[2]

There are more than 25 schools in the camp and classes are hugely overcrowded besides having limited resources. In the camp there is one place that has internet access. The project became a burden because of the costs. Timmers created a crowdfunding campaign to collect money to ship a solar suitcase, 20 laptops, his personal computer and equipment for internet infrastructure. In the camp there was a team formed by teachers who conducted Skype sessions with students in allocated schools in the camp.

The Skype calls were occurred on a quarterly basis in-line with the schooling periods which is nine months a year and three months during the holidays with mobilized students from the community.

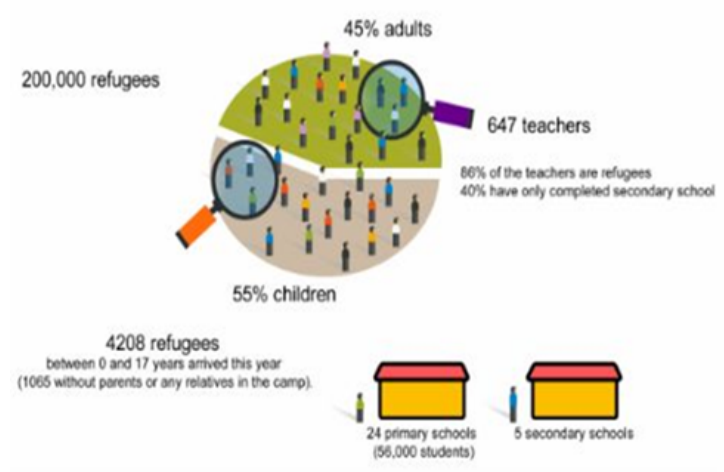

Figure 1: The Kakuma refugee camp. [3] 
In the camp one of the biggest challenges was power issues. This make it impossible to have a Skype call with students from different parts of the world. A sustainable solution to provide solar power was implemented.

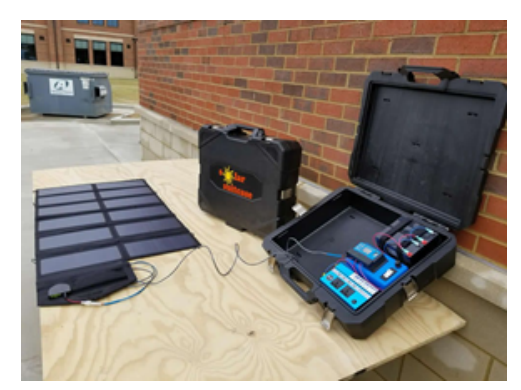

Figure 2: The Solar Suitcase was developed by Koen Timmers and Brian Copes.

This suitcase has a folding solar panel and offers free and sustainable power supply to schools who do not have access to electric power. The Solar Suitcase is mobile and allows to charge laptops, phones, during the day. [2]

\section{Implementing the Kakuma Project in Argentina}

Several teachers in Argentina have joined the Kakuma Project back in 2016 to open their classroom door to the world. Menezes (2014, [4]) points out the importance for teachers to plan opportunities for students to interact and make connections with each other. The first Skype lesson with Argentine students took place in Buenos Aires. The Argentine students knew they would be representing not only their school but also their country. Students had to do an extensive research on refugee camps. This was going to be their first time interacting with students from a refugee camp. 


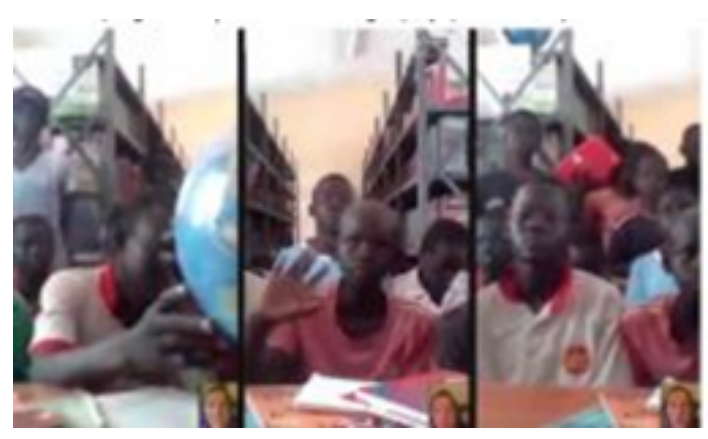

Figure 3: Jennifer Verschoor teaching Geography in 2016
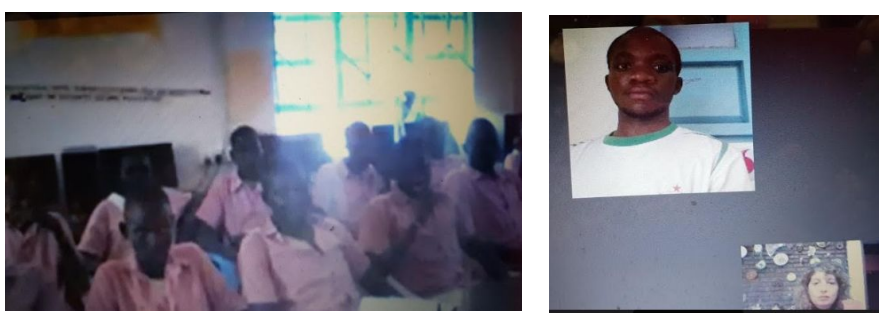

Figure 4: María José Giavedoni from Capitan Bermudez in Santa Fe in 2017.
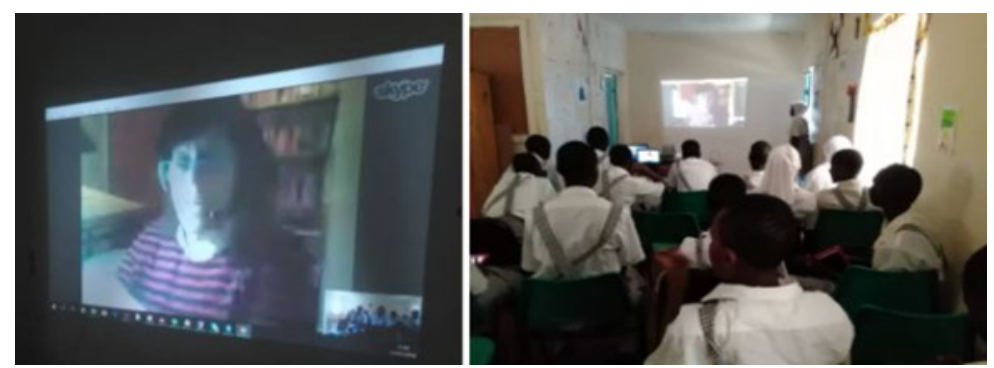

Figure 5: Susana Canelo teaching Math in the Angelina Jolie Girl's School in 2018

According to Susana Canelo from Del Valle 'I'm an architect and choose a math topic on Model Making The teen girls looked interested. We had a blast. I was asked to say "hello" in Spanish, so we had fun sharing words in both mother tongues. You can see them laughing at the end of the class, because I said in perfect Swahili: "Hakuna Matata". 


\section{Project-based learning in schools}

Project-based learning fosters a sense of responsibility and collaboration in each student. The Kakuma project is a clear example of world-improving projects. Students become the center of their own learning process and they generate content to impact the life of other students.

In this study, an online survey was created to evaluate the learning challenges and achievements. Several teachers from Argentina answered the survey after participating in an online class with Kakuma students. Up to date a total of 120 students from Argentina and more than 400 refugee students were able to learn from each other by creating online content and sharing knowledge.

Our research, based on the answers provided by Argentine teachers, has shown that student ownership improves once they are engaged in activities that have a real impact in the world they live in. Maria Jose Giavedoni from Capitan Bermudez in Santa Fé her students were eager to learn. During the Skype call they asked questions and completed all the exercises. They were active participants.

Gunawardena (1995, [5]) support the importance of teachers and course designers in developing competencies in planning virtual spaces and activities during which interactions among students can take place. The social and cognitive presences help foster and support discourse among the students. As stated in the survey the students engaged safely in their learning environment. Argentine teachers created a climate for motivation and facilitation. They regulated the learning by generating a social presence that fostered interaction and sharing even beyond what was planned for the class.

As stated by Susana Canelo from Del Valle "Many teachers making a difference, building bridges, changing so many lives. In fact it's a dream come true." Susana Canelo from Del Valle, Buenos Aires, Argentina 


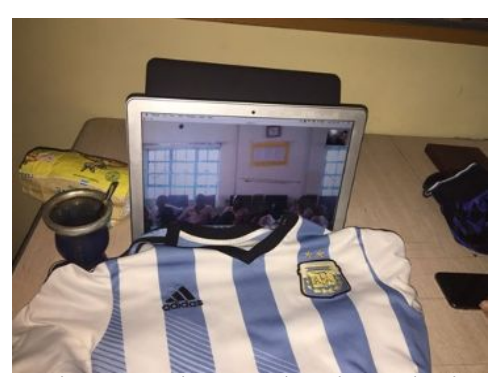

Figure 6: Argentine students sharing their culture with Kakuma Refugees.

\section{Conclusion}

This paper has tried to provide a glimpse of the intense work that is done to provide free education to African refugees. This study focused on a limited group of teachers who participated in the Kakuma Project from Argentina. Our future challenge is to measure further impact on learning by evaluating some indicators for teaching presence such as discourse facilitation, and direct instruction as stated in the frameworks of Garrison and Gunawardena[5]. Koen Timmers has decided to offer new learning opportunity to the refugees by creating a Kakuma Academy using videos. The video lessons are going to be created covering the official Kenyan curriculum. This way students can learn anytime, and at their own pace. The videos should be 15 minutes maximum using a screen recording tool and they will be published at academy.projectkakuma.com (still under development). Future research should examine the impact Kakuma Academy should have on camp refugees in order measure their impact on learning.

Nicole Bertucci, a 16-year-old student from Buenos Aires, said that participating in the project was the most amazing opportunity that could be given to a student. You are able to teach about your culture to a whole class on the other side of the world. It is a once in a lifetime opportunity that teaches you respect and learn about other cultures. 


\section{References}

[1] Timmers, Koen (2018) Project Kakuma: 150 Educators Across 6 Continents Offering Free Education to African Refugees via Skype. Retrieved May 12, 2019, from https://blog.education.nationalgeographic.org/2018/02/15/project-kakuma-150-educatorsacross-6-con tinents-offering-free-education-to-african-refugees-via-skype/

[2] Kakuma Project. https://www.projectkakuma.com/

[3 ]Koen Timmers http://www.koentimmers.be/projects.html

[4] Menezes, A. M. C. (2014). A vivência da presença social: histórias de um curso online para professores de Inglês. M.A. Thesis. Universidade Federal de Uberlândia. Retieved from http://ufuanamariamenezes.blogspot.com.br/.

[5] Gunawardena, C. N. (1995) Social presence theory and implications for interaction and collaborative learning in computer conferences. International Journal of Educational Telecommunications, 1(2),147-166. 